\title{
Distributed Control of a Fault Tolerant Modular Multilevel Inverter for Direct-Drive Wind Turbine Grid Interfacing
}

\author{
Max A Parker, Li Ran, Senior Member, IEEE, and Stephen J Finney
}

\begin{abstract}
Modular generator and converter topologies are being pursued for large offshore wind turbines to achieve fault tolerance and high reliability. A centralized controller presents a single critical point of failure which has prevented a truly modular and fault tolerant system from being obtained. This study analyses the inverter circuit control requirements during normal operation and grid fault ride-through, and proposes a distributed controller design to allow inverter modules to operate independently of each other. All the modules independently estimate the grid voltage magnitude and position, and the modules are synchronised together over a CAN bus. The CAN bus is also used to interleave the PWM switching of the modules and synchronise the ADC sampling. The controller structure and algorithms are tested by laboratory experiments with respect to normal operation, initial synchronization to the grid, module fault tolerance and grid fault ride-through.
\end{abstract}

Index Terms-Distributed control, modular generator, multilevel inverter, PWM interleaving, phaselock loop, estimation, fault tolerance, current control, wind turbine, CAN bus

\section{INTRODUCTION}

$\mathbf{O}$ FFSHORE wind power is set to become an increasingly important source of energy, and the economics of offshore wind are driving the need to develop larger wind turbines, but difficulty of access for repair means that reliability is of critical importance in minimising operational costs [1]. As the gearbox on the larger turbines is a significant source of downtime, due to the time and equipment required for replacement, direct-drive turbines which eliminate the gearbox could offer greatly increased turbine availability and lower maintenance costs [2].

Existing direct-drive turbines have been found to suffer higher failure rates for the generator and fully-rated power electronic converter than the geared equivalent, and this combined with the higher initial cost has lead to a higher total cost of ownership for onshore use [3]. However, it has also

Manuscript received June 15, 2011. Accepted for publication January 6, 2012.

Copyright (C)2011 IEEE. Personal use of this material is permitted. Permission from IEEE must be obtained for all other users, including reprinting/ republishing this material for advertising or promotional purposes, creating new collective works for resale or redistribution to servers or lists, or reuse of any copyrighted components of this work in other works.

Max A Parker was with the School of Engineering, Durham University and is now with the Department of Electrical and Electronic Engineering, University of Strathclyde, Royal College Building, 204 George Street, Glasgow, UK, G1 1XW (e-mail: max.parker@strath.ac.uk)

Li Ran is with the School of Engineering, Durham University, South Road, Durham, UK, DH1 3LE (e-mail: li.ran@durham.ac.uk)

Stephen J Finney is with the Department of Electrical and Electronic Engineering, University of Strathclyde. been suggested that the direct drive design has the greatest scope for reliability improvements [2], and for offshore use, the difficulty of access could tip the economic balance in favour of direct-drive if the availability can be improved. Fault tolerance - the ability for the turbine to continue functioning at reduced power when part of the generator or converter has failed - would increase the turbine availability, and is much easier to achieve on a generator or converter than on a gearbox.

Larger turbines are also leading to increased interest in multilevel converters, to increase the generator voltage and reduce the output voltage distortion for a given switching frequency [4]-[9]. The converter usually proposed is the 3level diode-clamped converter, producing a $3.3 \mathrm{kV}$ output with 4500V switching devices [6], [7], [9]. A larger number of levels would reduce the output voltage distortion, reducing the size of the output filter and allowing the use of cheaper switching devices with a lower voltage rating for the same output voltage [5]. Alternatively, a higher output voltage could be achieved in order to eliminate the grid coupling transformer [10], [11]. However it is difficult to control the separate DC link voltages on a diode-clamped converter with more than 3 levels [6], [12]. Hybrid multilevel converter designs have been proposed to improve the DC voltage control, but are complicated designs with many components [5].

A significant criticism of multilevel inverters, particularly those with a large number of levels, is that the increased component count will increase the failure rate of the converter. However, it has also been shown that a multilevel inverter featuring fault tolerance will have a significantly greater reliability, greater than that of a conventional 2-level inverter [13]-[15].

Of the main multilevel converter designs, the cascaded $\mathrm{H}$ bridge inverter has the lowest component count for a given number of levels, and does not suffer from DC-link voltage balancing issues [10], [12]. It is also simple to design an inverter constructed from a large number of identical modules, which can reduce costs through mass production of modules. Fault tolerance is achieved by designing the inverter to be tolerant of module faults [13], [14]. The main disadvantage with this type of inverter is that it requires a large number of isolated voltage sources to supply the individual modules, which are supplied by an expensive multi-winding transformer in commercial implementations [13].

The type of large multipole generator used in direct drive wind turbines can easily be wired with many individual coils, which can be used to supply the individual modules of the 
converter. A fault tolerant modular cascaded multilevel inverter has been designed [10], the structure of which is shown in Fig.1a, where each output phase consists of a string of modules, shown in Fig.1b. Coils are connected to the modules through boost rectifiers, and fuses are used to protect the coils from high currents in the event of a short circuit failure of the module semiconductors. The boost rectifiers are controlled by a microcontroller-based controller on each module to achieve a sinusoidal coil current, and the current magnitude is controlled to regulate the module DC-link voltage [16].

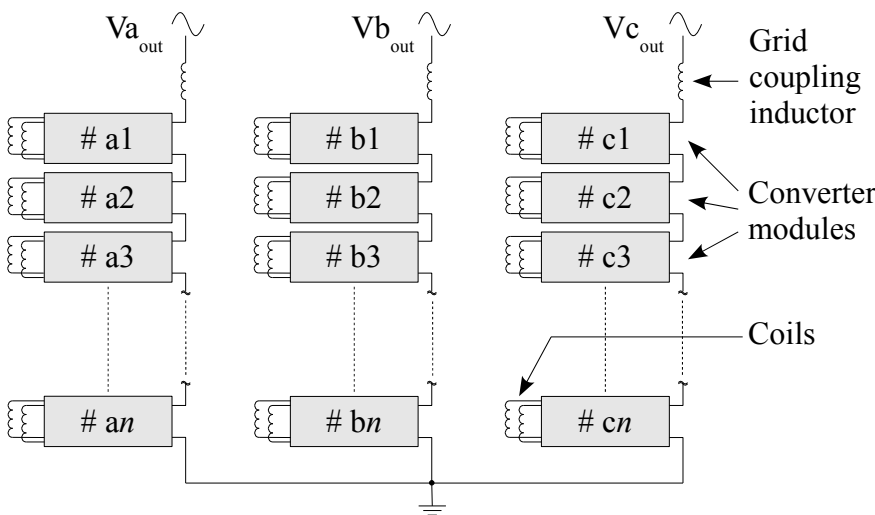

(a)

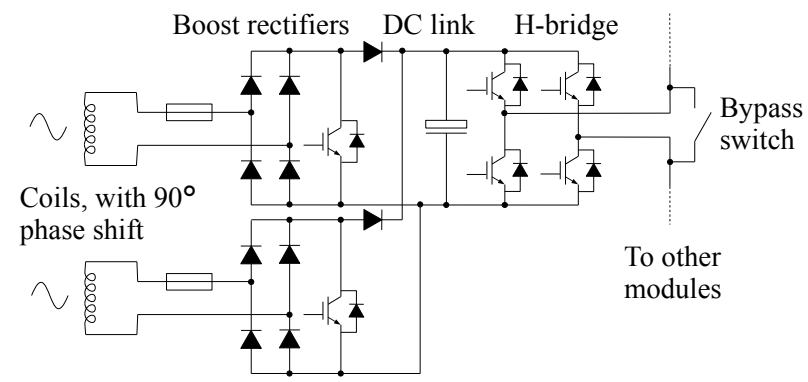

(b)

Fig. 1. Structure of the proposed grid interface converter. (a) Overall converter structure for three-phase output. (b) Structure of an individual converter module.

Generator designs exist where the coils are non-overlapping, potentially resulting in low mutual inductance between them [17], [18]. Connecting sets of coils through separate converter modules allows tolerance of coil faults, as the low mutual inductance means that a short circuit in one coil should have a minimal effect on the adjacent coils, and can be cut off by fusage [19]. Hybrid designs also exist in which a low speed multi-pole generator is driven through a single stage gearbox, resulting in a cheaper and lighter generator compared to truly direct drive [20], and these could be connected in the same way.

While existing implementations of such an inverter, including previous implementations of the design used in this project [10], can be made tolerant of power electronics faults, they rely on a central controller. The controller either provides the module switching pulses directly, or provides a timing signal synchronised to the grid voltage, from which the module controller can derive the switching pulses for the H-bridge [21]. The use of a central controller represents a single critical point of failure for the converter, and the failure rate of control electronics within wind turbines has been found to be similar to that of the power electronic converter [2]. A distributed control system, which replaces the central controller for both switching control and tracking the grid voltage, is desirable for a more fault tolerant converter, and has not been documented for an inverter based on series-connected modules. Such a control system is described in this paper.

Parallel connection of voltage source converters, using either a DC or AC bus, is common in power supply or distributed generation applications, to achieve redundancy and improved current capacity and harmonic performance. Distributed control systems exist using both wired and wireless synchronisation methods, to achieve current sharing between converters and interleave the switching to reduce the current harmonics [22]-[25]. However, the parallel connection allows each module to sense the bus voltage, and the current controllers operate independently, and the interleaving of the module switching can be carried out at a lower bandwidth as the stability of each current controller is not affected by the level of interleaving.

In the proposed converter, the modules are connected in series, meaning that they cannot detect the AC bus voltage, and they share the same current, requiring a distributed current controller structure which has not previously been described in literature. The performance of a distributed current controller is dependent on the interleaving of the module switching waveforms, as bad interleaving will lead to a significant voltage distortion, leading to current distortion which could cause instability in the current controller. For this reason, a wired communication link is used to allow the modules to synchronise with each other in the fastest and most accurate way, although this represents a single point of failure for the system, which is undesirable. It would be possible to provide a second redundant communications bus, but this would increase the cost.

For ease of implementation, the 3-phase inverter has been designed around having the neutral point grounded, allowing each output phase to be considered as a separate single phase inverter. In the event of the failure of a module, a switch is activated to bypass the module, which is triggered by the loss of a control signal from the module controller. The total output voltage of the inverter will be reduced, so the output voltages of the remaining modules must be quickly raised to compensate and the switching instances re-calculated to remove the distortion in the output waveform. This has been demonstrated on a small scale test system [16]. In this system, the number of module faults that can be tolerated depends on the amount by which the module DC-link voltages can be raised. Allowing the neutral point position to shift could allow tolerance to a greater number of module faults with a smaller DC-link voltage rise [13], [26].

Two earlier papers, [10] and [16], described the fundamental configuration of the system, and its control during normal power tracking and for fault tolerance. This paper intends to show the distributed control characteristics which have not yet been seen in wind turbines. As well as operation in normal conditions, operation during grid faults will also be considered, this being traditionally difficult to fulfil. 


\section{Grid FAult Ride-Through Considerations}

Grid faults will cause a voltage dip viewed at the wind turbine terminals, and the grid codes of different countries place requirements on what level of voltage dip the turbine must ride through without disconnecting. The low voltage ride-through requirements of the UK grid code are shown in Fig. 2 for the first 3 seconds. The turbine must also further ride through for 3 minutes at $85 \%$ of nominal voltage and indefinitely at $90 \%$ of nominal voltage [27]. The grid codes of other countries are similar, with some requiring the turbine to ride through brief voltage dips to zero volts at the turbine terminals.

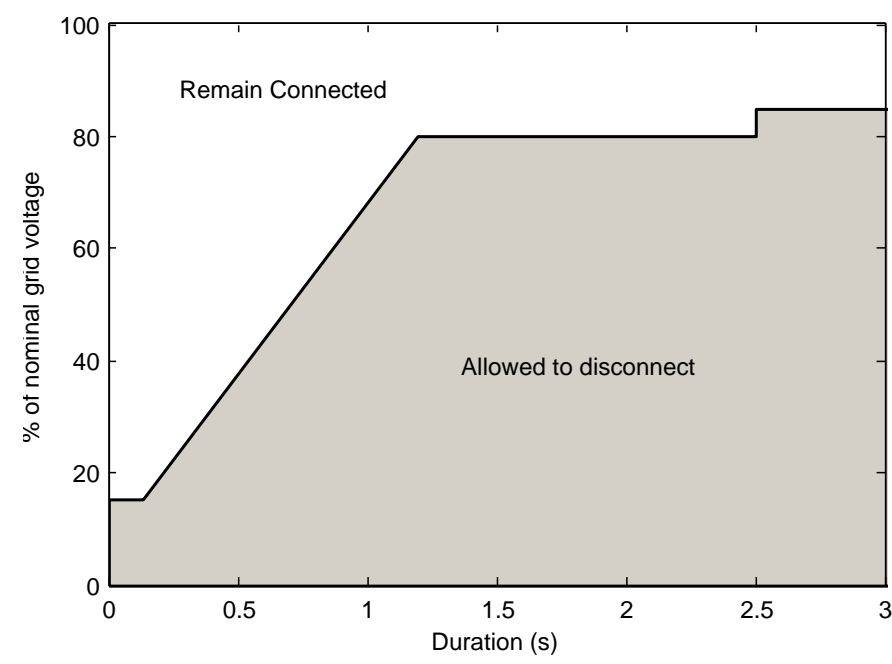

Fig. 2. Voltage dip ridethrough requirements from UK grid code

These requirements apply for both symmetrical and asymmetrical faults. As the test rig for this research only features a single phase string of modules, the response of other phases cannot be represented, and so only faults affecting that or all phases equally will be considered. This is sufficient because the output phases do not share any DC-link capacitors in the modules.

In a conventional controller for a grid-connected inverter [28], the grid voltage is measured and a phaselock-loop (PLL) is used to derive a reference value for the instantaneous grid voltage magnitude and angle, $\hat{V}_{g}$ and $\hat{\theta}$, assuming that the grid voltage is of the form $v_{g}=V_{g} \sin \theta$. The inverter output current is regulated in the rotating reference frame aligned to $\hat{\theta}$, using a proportional-integral (PI) controller to vary the duty cycle of the inverter. The output of the current controller is added to a feedforward voltage, which is the voltage calculated to achieve the desired current in the steady state, based on $\hat{V}_{g}$ and $\hat{\theta}$.

When a grid fault occurs, $\hat{V}_{g}$ will take time to react to the drop in the grid voltage due to the dynamics of the voltage reference loop, and an incorrect feedforward voltage will be calculated and applied. The current controller is able to prevent the sudden surge of reactive power which would occur, and which would otherwise exceed the thermal limits of the switching devices. $\hat{V}_{g}$ should then adjust to the new grid voltage, so the correct feedforward voltage is calculated. Four aspects of the proposed distributed controller mean that this approach is difficult to implement:

- The low distortion in the inverter voltage waveform means that the inverter only requires a small grid coupling inductor to comply with harmonic limits. Therefore the current will rise rapidly in response to a drop in grid voltage, requiring a fast controller to keep the current within safe limits.

- If a PI controller is used to regulate the current in each module, then the values of the integrators must be synchronised between modules so that they all behave identically. For a sufficiently fast controller, a communications link with an extremely high bandwidth and low latency is required between modules, increasing the cost and processing overhead.

- As the modules are cascaded, they will not be able to directly measure the grid voltage, so an observer system must be used, which will use the inverter current to estimate the voltage.

- If a current controller is not used, then the current will be controlled by the feedforward voltage, and the bandwidth of the controller would depend on the speed of the grid voltage tracking. As the grid voltage references must be synchronised between modules, a high bandwidth communications link between modules would still be required to limit the current.

It is proposed that a proportional controller be used in each module to limit the current during grid faults, and will operate in the stationary reference frame, with a sinusoidal reference current. This will operate independently on all modules, and will not require synchronisation between modules. The current will be controlled in normal operation using a feedforward voltage based on reference values of the grid voltage angle and magnitude, calculated on each module by an observer system and synchronised between modules using a communications link. As the initial current limiting is not dependent on the bandwidth of the communications link, a lower bandwidth link can be used.

The inverter controller must also be able to continue tracking the grid voltage angle with the reduced magnitude during a fault. The reduced grid voltage, and the thermal limits on the inverter current, will limit the amount of real power that can be exported by the turbine. If the turbine is operating at a high output power, the sudden reduction in power will cause the DC-link voltage to rise, and the DC-link voltage controller will need to quickly react to reduce the input power from the rectifiers. The DC-link voltage controller has been described in [16], and the controller bandwidth is limited as the DC-link voltage contains significant ripple at twice the grid frequency, which must be avoided in the coil current control.

\section{TEST SETUP}

The distributed controller was designed around the small scale test system, as a replacement for the existing centrally controlled design. The test system implements a $2.5 \mathrm{~kW} 25$ level single phase inverter, with $230 \mathrm{~V}$ output voltage, consisting of 12 converter modules fed from two axial-flux permanent 
magnet generators each with 12 isolated coils. Each module is connected to two coils, which have a $90^{\circ}$ phase shift, to provide constant power. The generators are driven by an induction motor through a reduction gearbox, connected to a variable speed drive. The test setup is shown in Fig.3.

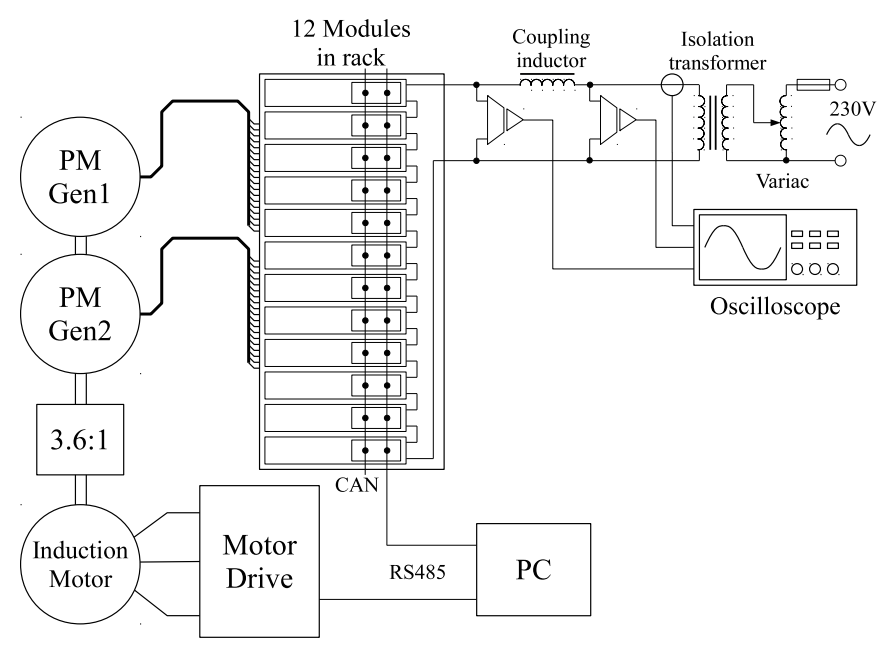

(a)

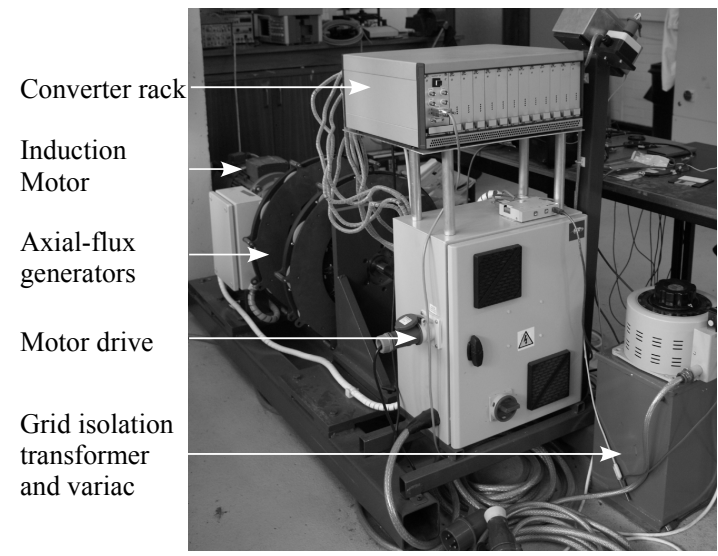

(b)

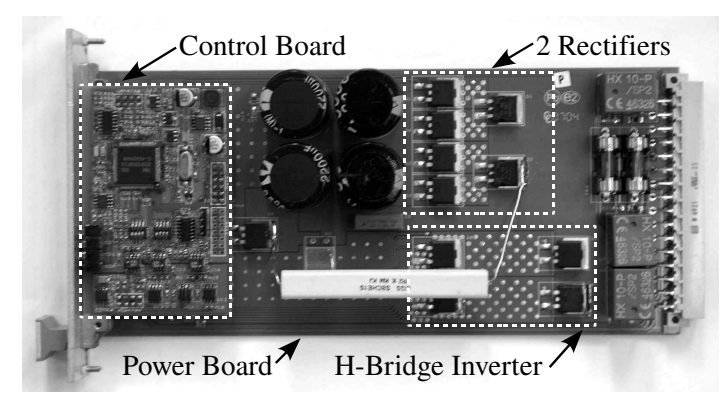

(c)

Fig. 3. Experimental system, featuring (a) System diagram (b) Test system arrangement, and (c) Individual converter module board

For the ease of access and programming, the converter modules are designed to plug into a eurocard subrack, which is mounted close to the generators. Each converter module consists of a power board, incorporating the switching devices, capacitors, gate drive and current and voltage transducers. Attached to the power board is a control board, developed around a TMS320F2808 microcontroller, which contains the peripheral devices required by the application. The control board also provides all the optically isolated communication interfaces. The control board samples the inverter output current, the DC-link voltage and the currents in the connected coils.

Synchronisation of the module grid voltage references is carried out over a CAN bus, which is a multi-master protocol, allowing any node to communicate with any other, and is designed for fault tolerance. CAN was chosen as it is implemented in hardware on many microcontrollers, without requiring extra ICs to be added, which would increase the cost and size of the control board. Other communication protocols implemented on the microcontroller, such as SPI and $\mathrm{I}^{2} \mathrm{C}$ are designed for short range communication between ICs, and are unsuitable for this application, and using an RS485 serial link would require the higher level protocols to be implemented in software, adding a significant processing overhead.

CAN uses a small message frame size and bit rates of up to $1 \mathrm{Mbps}$, so message latency is low, which is ideal for synchronisation purposes [29], it also has a high noise immunity. As standard, CAN does not include any galvanic isolation, which is required in this application, so this is added using opto-couplers between the microcontroller and the CAN transceiver. A full size converter will require higher isolation voltages, possibly using optical fibres, so CAN may not be appropriate, or may require significant adaptation.

CAN is tolerant of faults in individual nodes, as each node is able to detect when it is not transmitting or receiving messages properly and ceases operation after a set number of errors. This will cause the module with the communication failure to cease operation, which the inverter is able to tolerate [16]. The fault response relies on the node controller being active, and a fault in which causes a faulty node to lock up the bus or a short circuit in the bus itself will prevent any communication between modules, causing the inverter to shut down. Starbased implementations have been designed which improve the fault tolerance [30].

Each message frame has an identification field, and if two messages are transmitted simultaneously the message with the lower value in the identification field will override the one with the higher value, which will be forced to stop transmitting until the bus is free. Because of this, message latency is highly deterministic, unlike most other communications protocols, and messages are assigned different priorities based on the value of the identification field. The identification field represents the contents of the message data rather than the intended receiver. Each message is received by all nodes on the CAN bus, and the individual CAN controllers can be programmed to accept messages or to ignore them without alerting the CPU, depending on the identifier.

A disadvantage of the CAN protocol is that each node must receive each bit of the message within the narrow time window before the next bit is sent, in order to be able to determine which message has the higher priority. This limits the maximum data rate and bus length, with $1 \mathrm{Mbps}$ only achievable with bus lengths of $20 \mathrm{~m}$ or shorter, although this is adequate for the proposed application. Faster fault-tolerant communication buses exist, such as FlexRay and Spacewire, 
which are designed for automotive and aerospace applications [31], but these are not implemented on any low cost microcontrollers, and would require extra hardware, increasing the control board size and cost.

The modules also feature an RS485 interface, implementing the MODBUS protocol, for communication with a host PC for data acquisition, and to vary the converter operating mode and setpoints. The inverter is connected to the grid through a $9 \mathrm{mH}$ coupling inductor.

\section{Distributed Controller Design}

A PWM switching scheme is used for the inverter switching, for ease of controllability during module and grid faults. Fundamental frequency switching gives lower switching losses, but during grid faults or voltage dips, the minimum voltage output of the inverter will be limited by the minimum DClink voltages of the modules, which due to the nature of the boost rectifier is determined by the turbine speed. Following a module fault, the output voltages of the remaining modules must be raised, which requires the DC-link voltages to be raised if fundamental frequency switching is used. This is slower than simply changing the modulation depth in a system with PWM switching, and could apply unwanted transient loads to the generator and turbine rotor.

For ease of implementation in a distributed system, and to equalise power sharing and switching losses between modules, a phase-shifted PWM system is used. This also allows the control system to be used with an inverter having a lower number of modules. As the power sharing between modules is unlikely to be exactly equal, the module DC-link voltages will need to be individually controlled. In this system, the DC-link voltage is held constant, by varying the rectifier current demand, and the duty cycle of the module inverter $\mathrm{H}$-bridge is determined by a reference voltage waveform, the magnitude and phase of which are selected to achieve the desired current output, to achieve the required power output. This is the opposite of the approach usually taken in gridconnected inverters.

To keep costs down, the grid coupling inductance should be as small as possible. The use of a multilevel converter provides an output voltage with low distortion while still using a low inverter switching frequency, which allows a much smaller inductor to be used than for standard 2- and 3-level converters. With the test system, an inductor providing a per-unit reactance of 0.045 was initially specified, although this was increased to 0.14 p.u. due to distortion in the background grid voltage.

The distributed controller consists of four inter-linked elements:

- A method to interleave the phase-shifted PWM carriers of the different modules. The PWM carrier on each module also determines the instance the ADC samples the grid current, which triggers the interrupt to run the control algorithms. Therefore, properly interleaving the module PWM carriers will ensure that the ADC sampling on all modules occurs simultaneously.

- A method to set the output voltage of each module to achieve the desired current, based on a reference value of the grid voltage magnitude and phase, and also to limit the current in the event of a grid fault. Current limiting must operate independently on each module due to the limited bandwidth of the CAN bus used for communications between modules.

- A PLL system to maintain a reference of the grid voltage angle and magnitude, based on the estimated grid voltage, and a method to synchronise the grid voltage references of all the modules.

- An observer system to estimate the grid voltage, based on the previously applied inverter output voltage and resulting current. This will run separately on all the module controllers, and the code should execute simultaneously if the modules are properly synchronised. In other words, the estimated grid voltage should be equal on all modules.

\section{A. PWM Interleaving and Sampling Synchronisation}

The inverter PWM carrier on each module, synthesised digitally in the microcontroller, operates at a frequency of $333 \mathrm{~Hz}$, and bipolar switching is used to double the effective module switching frequency while keeping the switching frequency of each individual leg at $333 \mathrm{~Hz}$ [32]. When interleaved properly, the 12-module inverter has an apparent switching frequency of $8 \mathrm{kHz}$.

Sampling of the inverter output current by the modules, and the operation of the control algorithm, is done at twice the apparent frequency, i.e. $16 \mathrm{kHz}$, in order to avoid aliasing, and is synchronised to the PWM carriers on each module. If the PWM carriers of each module are properly interleaved, then the modules should all be sampling the current at the same time.

Interleaving is carried out by having each module send out a message frame on the CAN bus whenever its PWM carrier reaches either the maximum or minimum value, while listening out for messages from other modules. Using timestamps for the received messages, provided by the CAN controller on the microcontroller, the control algorithm can calculate the time difference between its PWM carrier and those of the previous and next modules in the sequence. The period of the module's PWM carrier can then be shortened or lengthened temporarily to minimise this difference, equalising the time period between messages, as shown in Fig.4.

If one module in the inverter fails, it will stop transmitting its synchronisation message. The remaining modules will then adjust their PWM carriers such that the gap in the switching waveform is eliminated, and the module PWM carriers remain equally spaced. This method is similar to an analogue synchronisation method for interleaved converters [33], and offers greater flexibility due to the digital implementation, but a lower maximum PWM switching speed due to the limited bandwidth and message timestamp resolution of the CAN bus and controller.

In practice, in order to conserve the bandwidth of the CAN bus, messages are only sent out every seventh PWM carrier maximum or minimum, resulting in 1143 messages sent per second from all 12 modules. The prototype inverter has 12 modules, and is designed to function with 11 or 10 modules. 


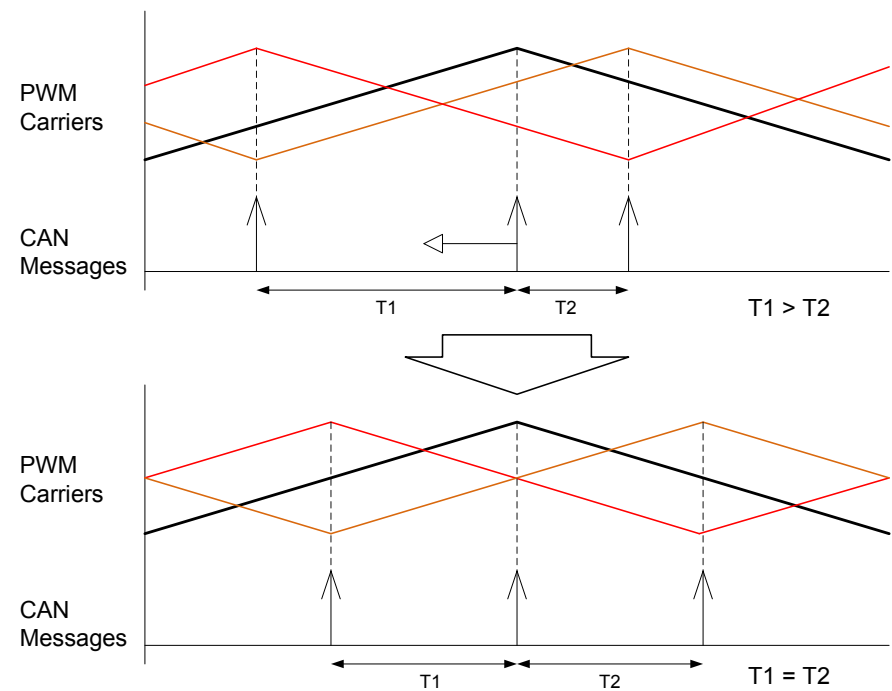

Fig. 4. Synchronisation and interleaving of PWM carrier waveforms

7 is not a factor of any of these numbers, so this method will still result in proper interleaving of the module PWM carriers. With a message frame of 44 bits in length (CAN message frame with standard identifier and no data), this will require a bandwidth of around 50kbps, a small fraction of the $1 \mathrm{Mbps}$ available.

\section{B. Current Control}

A single phase string of $n$ modules is shown in Fig.5. Each module $m$ produces an output voltage $v_{m}$, and the total output voltage $v$ is the sum of the outputs of the individual modules, given by (1). The grid is modelled as a voltage source, of voltage $v_{g}$, and a coupling inductor of inductance $L$ and resistance $R$ is used. It is assumed that the grid inductance will be significantly lower than that of the coupling inductor. A current $i$ will flow.

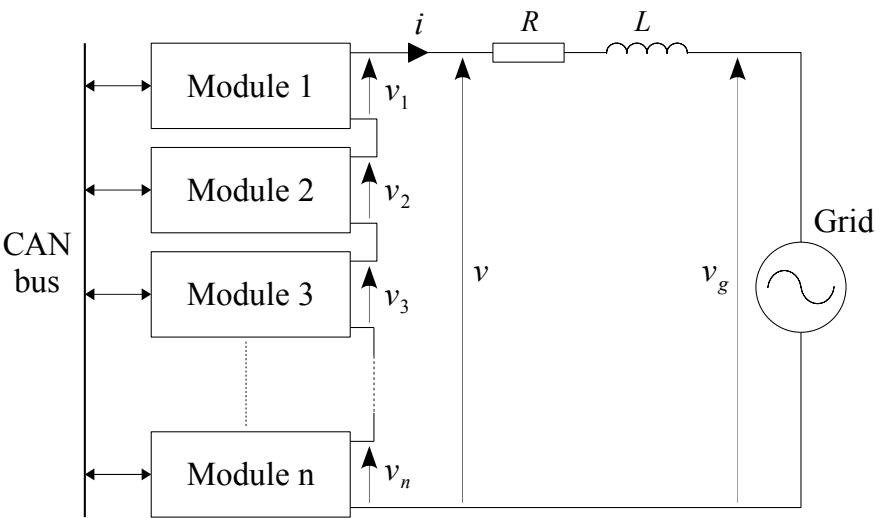

Fig. 5. Connection arrangement for a single phase string of modules.

$$
v=\sum_{m=1}^{n} v_{m}
$$

Control of the inverter current is primarily achieved using a feedforward system, which calculates the inverter voltage necessary to achieve the desired current based on reference values of the grid voltage magnitude and angle from a PLL [34]. The relationship between $v, i$ and $v_{g}$ is given by (2). The grid voltage is assumed to be sinusoidal, of the form $v_{g}=V_{g} \sin \theta$, where $V_{g}$ is the magnitude of the grid voltage and $\theta$ the angle. $v$ and $i$ are also assumed to be sinusoidal.

$$
v=v_{g}+i R+L \frac{\mathrm{d} i}{\mathrm{~d} t}
$$

Calculation of the feedforward voltage takes place in the rotating reference frame, with the q-axis aligned to the reference grid voltage angle $\hat{\theta}$ from the PLL. The value of the feedforward voltage $V_{f f d, q}$ required to achieve an inverter current $I_{d, q}^{*}$ is given by (3), where $\hat{\omega}$ is the reference grid frequency and $\hat{V}_{g}$ is the reference grid voltage magnitude.

$$
\begin{aligned}
{\left[\begin{array}{c}
V_{f f d} \\
V_{f f q}
\end{array}\right]=} & {\left[\begin{array}{c}
0 \\
\hat{V}_{g}
\end{array}\right]+\left[\begin{array}{cc}
R & 0 \\
0 & R
\end{array}\right]\left[\begin{array}{c}
I_{d}^{*} \\
I_{q}^{*}
\end{array}\right] } \\
& +\left[\begin{array}{cc}
0 & -\hat{\omega} L \\
\hat{\omega} L & 0
\end{array}\right]\left[\begin{array}{c}
I_{d}^{*} \\
I_{q}^{*}
\end{array}\right]
\end{aligned}
$$

Two current control modes, using the feedforward voltage calculated with (3), are implemented, and these are shown in Fig.6. For normal operation, shown in Fig.6(a) the inverter acts as a voltage source, producing a sinusoidal voltage, and allowing the grid to draw any current harmonics corresponding to the grid voltage.

On the occurance of a grid fault or during synchronisation, the grid voltage could be significantly different from the value previously estimated, leading to an incorrect feedforward voltage being applied until the grid voltage estimator catches up with the change in grid voltage. This will lead to a rapid rise in the current due to the low grid coupling inductance. The limited communication bandwidth between modules limits the bandwidth of the voltage estimator, so the feedforward voltage cannot be updated quickly enough to limit the current. For these scenarios a current limiting mode was implemented, shown in Fig.6(b), based on using a proportional controller to limit the current in the stationary reference frame. This mode will cause the inverter to produce a sinusoidal current waveform whatever the shape of the grid voltage waveform.

In the basic control scheme using PWM switching in each module, shown in Fig.6(a), the feedforward voltage is converted to the fixed reference frame using the $e^{-j \theta}$ block and the estimated grid voltage angle $\hat{\theta}$. The voltage is then used to set the PWM duty cycle based on (4), where $V_{d c}$ is the DC-link voltage in the module and $n$ the number of modules. As the inverter output voltage $v$ is the sum of all the module voltages, the time-averaged output voltage will equal $v_{f f}$.

$$
d=\frac{1-v_{f f}}{n V_{d c}}
$$

In the current limiting mode of operation, shown in Fig.6(b), the same feedforward calculation is used. Additionally, the reference demand $I_{d, q}^{*}$ is converted to the fixed reference frame current demand $i$, which is used in a proportional controller to modify the duty cycle and force the current to follow the demand. The use of a proportional controller, 


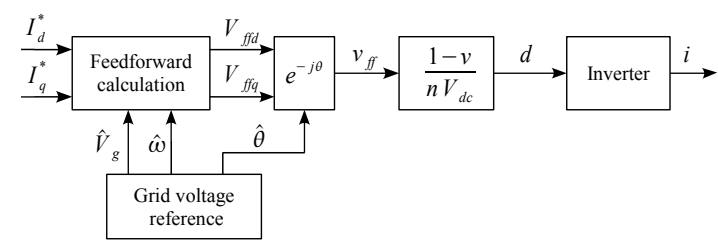

(a)

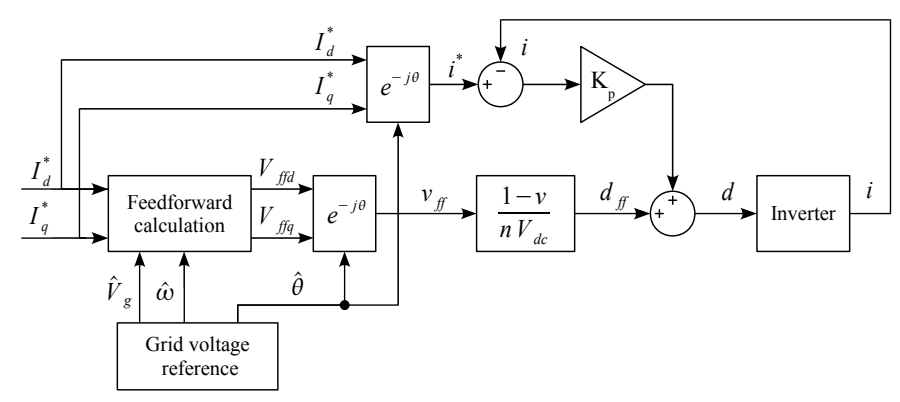

(b)

Fig. 6. Inverter current control modes, featuring (a) Feedforward control with PWM switching, (b) Current limiting control with PWM switching.

and the fact that all modules should be sampling the current simultaneously, means that the current limiting action will be identical in all modules so long as their grid voltage references are synchronised. This allows the current limiting controllers in each module to function independently, with a much higher bandwidth than that of the CAN bus connecting them.

The main disadvantage with using a proportional controller is that there will be a steady state error between the grid current and current demand, with the size of the error depending on the proportional gain. This will only occur immediately after a grid fault or grid synchronisation, when the estimated grid voltage is significantly different from the actual voltage, resulting in an incorrect feedforward voltage being used.

\section{Grid Voltage Reference Loop}

A reference value of the grid voltage angle $\hat{\theta}$, is maintained on each module using a phaselock loop (PLL), and is used for transformation to and from the rotating reference frame. The PLL works by comparing $\hat{\theta}$ with the measured grid voltage angle $\theta$, and calculating the phase difference $\phi . \phi$ is then passed through a loop filter, the output of which is the reference frequency $\hat{\omega}$, which is integrated to give $\hat{\theta}$. As the grid frequency varies, the loop controls $\hat{\omega}$ to minimise $\phi$, meaning that $\hat{\theta}$ tracks $\theta$. $\theta$ cannot be measured directly, and must be estimated from other parameters, the method for which is described in the next section.

A proportional-integral (PI) controller is used for the loop filter in order to avoid a steady state error between the grid angle reference and the actual grid angle, which would result in the current being different from the demand. The use of a PLL provides stable tracking of the grid voltage angle, without a phase delay, and with good noise rejection, and the level of noise rejection depends on the bandwidth of the loop filter. The grid voltage magnitude reference, $\hat{V}_{g}$, is obtained by filtering the estimated instantaneous value of the magnitude using an integrator, which will be expanded on later in this section.
This system requires $\hat{\theta}$ to be synchronised between modules, which is similar to the problem of synchronising clocks between multiple nodes in a distributed system [35], especially a system where a relative time is synchronised between nodes rather than an absolute time obtained externally. Both centralised and decentralised algorithms of varying complexity exist.

A simple decentralised method of synchronising reference angles, described in [35], is for each module to periodically broadcast what reference angle it has, onto the network, with the modules collecting the values from each other and updating their own reference angle with the average. A better algorithm, especially designed for use with the CAN system, is described in [36], but for simplicity the simple averaging system will be used.

Instead of having all the modules periodically broadcast their reference values for grid voltage angle and magnitude, the modules attach these values to the message frames used for interleaving the PWM switching. When a module receives the message from another module, the message timestamp is recorded. When the modules interrupt service routine (ISR) runs, the message timestamp and current value of the timer can be used to compensate for the delay between reception of the message and operation of the ISR.

The structure of the complete grid voltage angle reference loop for one module is shown in Fig.7. The 'Grid Phase Detector' block, to be described in the next section, estimates the phase difference $\phi_{2}$ between the grid voltage angle and the reference angle $\hat{\theta}$. The values of $\hat{\theta}$ from other modules, represented as $\hat{\theta}_{n}$, are received on the CAN bus individually, one module at a time. The phase difference between the most recently received $\hat{\theta}_{n}$, and the local $\hat{\theta}$, is is labelled $\phi_{1}$.

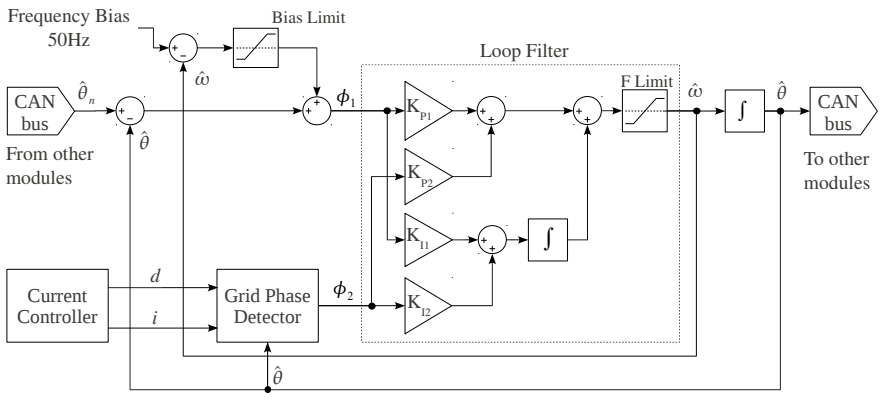

Fig. 7. Distributed grid voltage angle reference

In the loop filter, $\phi_{1}$ and $\phi_{2}$ are combined, through separate proportional and integral gains $K_{P 1,2}$ and $K_{I 1,2}$, and the filtering effect of the PI controller is used to average the values of $\phi_{1}$ from different modules. The separate gains allow the influence of the two inputs on the reference frequency $\hat{\omega}$ to be adjusted, and it was found that using the same proportional and integral gains for both inputs gave an acceptable performance. A system is also included to bias the frequency towards $50 \mathrm{~Hz}$ as, in the absence of a detectable grid voltage, such as when disconnected, islanded or during a severe voltage dip, the frequency will tend to drift.

The structure of the grid voltage magnitude reference for one module is shown in Fig.8, and follows a similar, but 
simpler structure to the angle reference loop. Again a system is used to bias the voltage magnitude reference towards $230 \mathrm{~V}$, the nominal grid voltage in the test system, to prevent it drifting when the system is not connected. An integral controller is required for this use, as it allows the voltage magnitude to be biased towards a particular value, while limiting the influence of the bias (through a saturation function) when the grid voltage is substantially different from the bias value, i.e. during a severe voltage dip.

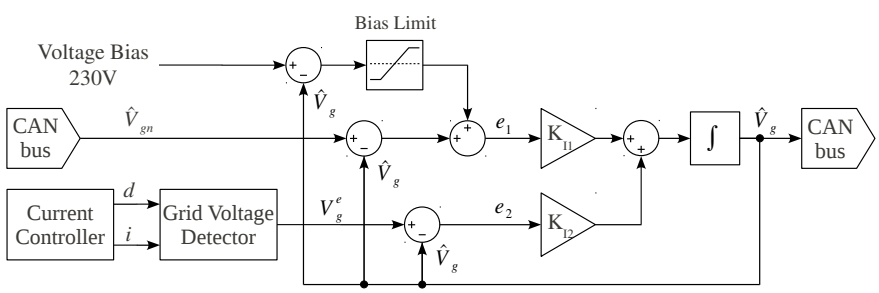

Fig. 8. Distributed grid voltage magnitude reference

\section{Grid Voltage Estimator and Phase Detector}

As the system is distributed between many identical modules, the grid voltage cannot be measured directly as this would require a central voltage sensor, defeating the purpose of having a distributed modular system. A method of estimating the grid voltage from the current is required, and a suitable algorithm is described in [34], which will operate independently on all modules.

Based on (2), the instantaneous grid voltage can be estimated if the inverter output voltage and current are known, along with the resistance and inductance of the coupling inductor. The instantaneous grid voltage is estimated in the rotating reference frame aligned to the reference value of the grid voltage angle, $\hat{\theta}$, as used for calculating the feedforward voltage. The estimated grid voltage $V_{g d, q}^{e}$ is given by (5), where $V_{d, q}$ is the voltage applied by the inverter in the previous controller cycle, and $I_{d, q}$ is the measured inverter current transformed into the rotating reference frame.

$$
\begin{aligned}
{\left[\begin{array}{c}
V_{g d}^{e} \\
V_{g q}^{e}
\end{array}\right]=} & {\left[\begin{array}{c}
V_{d} \\
V_{q}
\end{array}\right]-\left[\begin{array}{cc}
R & 0 \\
0 & R
\end{array}\right]\left[\begin{array}{c}
I_{d} \\
I_{q}
\end{array}\right] } \\
& -\left[\begin{array}{cc}
0 & -\hat{\omega} L \\
\hat{\omega} L & 0
\end{array}\right]\left[\begin{array}{c}
I_{d} \\
I_{q}
\end{array}\right]
\end{aligned}
$$

If the inverter is not operating in the current limiting mode, the inverter output voltage $V_{d, q}$ is assumed to be the same as the feedforward voltage calculated by the current controller in the previous cycle. This assumes that all the modules have calculated and applied the same feedforward voltage, which would be the case if their grid voltage references and current demands are identical. If the current limiting mode is activated, the applied voltage must be calculated from the previously applied duty cycle and the DC-link voltage, according to (4), as the duty cycle will have been modified by the current limiting controller. The voltage estimator, for the current limiting mode, is shown in Fig.9, and combines

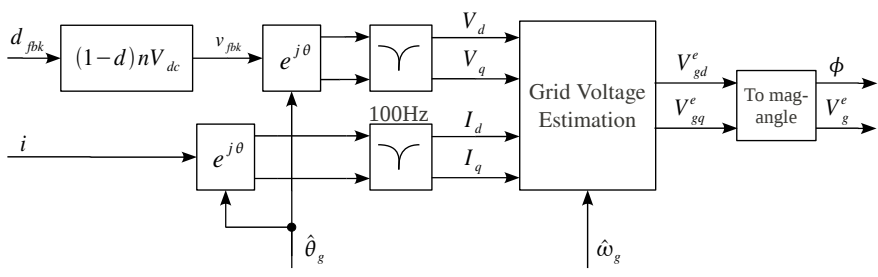

Fig. 9. Grid voltage and phase detector

the Grid Phase Detector block in Fig.7 and the Grid Voltage detector in Fig.8.

Using a single-phase reference transformation results in a significant ripple in the transformed signals, at twice the grid frequency, and this is removed using notch filters tuned to $100 \mathrm{~Hz}$. The dynamics of the notch filters must be considered when designing the loop filter. As $V_{g d, q}^{e}$ are calculated in the rotating reference frame aligned to $\theta$, the angle between the vector $V_{g d, q}^{e}$ and the q-axis is the angle $\phi_{2}$, used in the PLL, while the magnitude of the vector is the estimated grid voltage magnitude $V_{g}^{e}$, used in the grid voltage magnitude reference loop.

\section{E. Selection of Loop Filter Parameters}

The PLL loop filter gains were selected to maximise the response speed while keeping the bandwidth below the notch filter frequency, to minimise the interaction with the notch filter. The selected gains give a bandwidth of $30 \mathrm{~Hz}$ and a damping ratio of 0.707 . The simulated response of the reference angle $\hat{\theta}$ to a unit step change in grid frequency is shown in Fig.10, in which the influence of the inter-module synchronisation system is ignored.

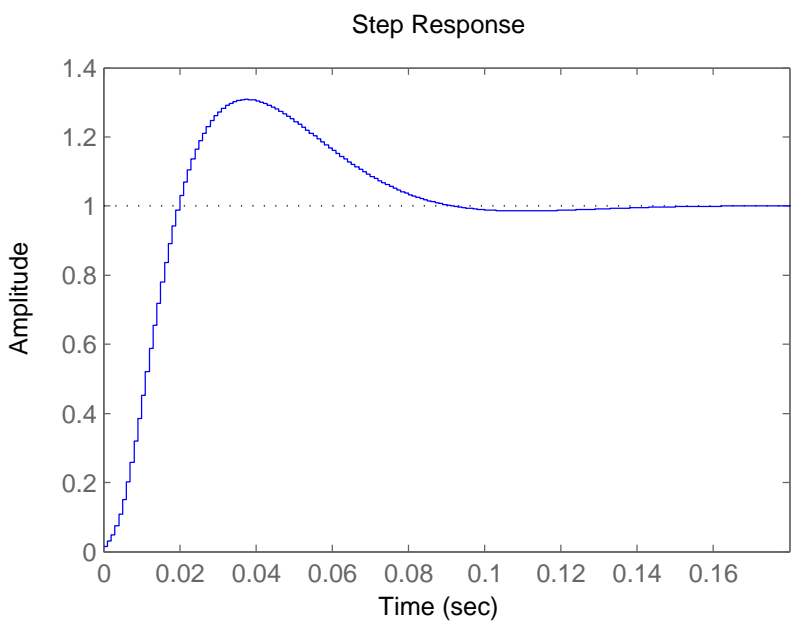

Fig. 10. Simulated step response of the grid angle reference loop

The integral gain of the voltage reference filter was selected to provide a high bandwidth, while keeping the closed loop poles a reasonable distance from those of the notch filter to prevent unwanted interactions, and a bandwidth of $50 \mathrm{~Hz}$ was achieved. The response of the voltage reference filter to a unit step change in input voltage is shown in Fig.11. The step response of the voltage reference, without including the notch 
filter, is also shown, and shows that the influence of the notch filter is within acceptable bounds.

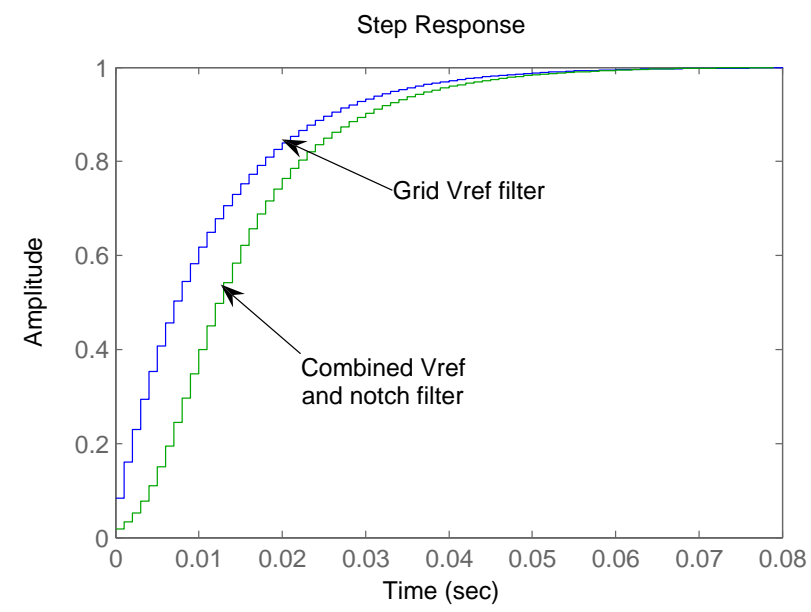

Fig. 11. Simulated step response of the grid voltage reference filter

\section{TESt Results}

All testing is based on using PWM switching in the inverter modules, with the DC-link voltage demand on all modules held constant at $32 \mathrm{~V}$.

\section{A. PWM Interleaving}

Activity on the CAN bus with the PWM carriers of all 12 modules synchronised is shown in Fig.12a. CAN uses differential signalling, where the signal is the difference between the voltages on two wires, which are labelled CAN High and CAN Low in the figure. The messages on the CAN bus are evenly spaced, so the PWM carriers will be interleaved. Fig. 12b shows the synchronisation error recorded by the module controllers. This is the error calculated by the module between its PWM carrier peak, and where the peak should be, based on the peaks of the next and previous modules in the sequence. This error is then used by the module to modify the timing of its own carrier.

The error signal shows a jitter of around $20 \mu \mathrm{s}$, and as the synchronisation pulses are sent out every seventh PWM carrier peak, this represents a jitter in the PWM carrier of $2.9 \mu \mathrm{s}$, which is small compared to the $3 \mathrm{~ms}$ time period of each PWM carrier. The error appears to oscillate, and it is expected that detailed modelling of the control action and CAN bus could result in a significantly lower jitter.

\section{B. Current Control}

Testing of the inverter current limiting operation was carried out by fixing the magnitude of the feedforward voltage, and shorting the inverter terminals. The inverter current demand is set to zero. The inverter current and voltage waveforms were recorded on an oscilloscope, and are shown in Fig.13a. The feedforward and applied voltages are recorded on the module controllers, as shown in Fig.13b for one module.

The proportional current controller is able to reduce the applied voltage and counteract most of the feedforward voltage,

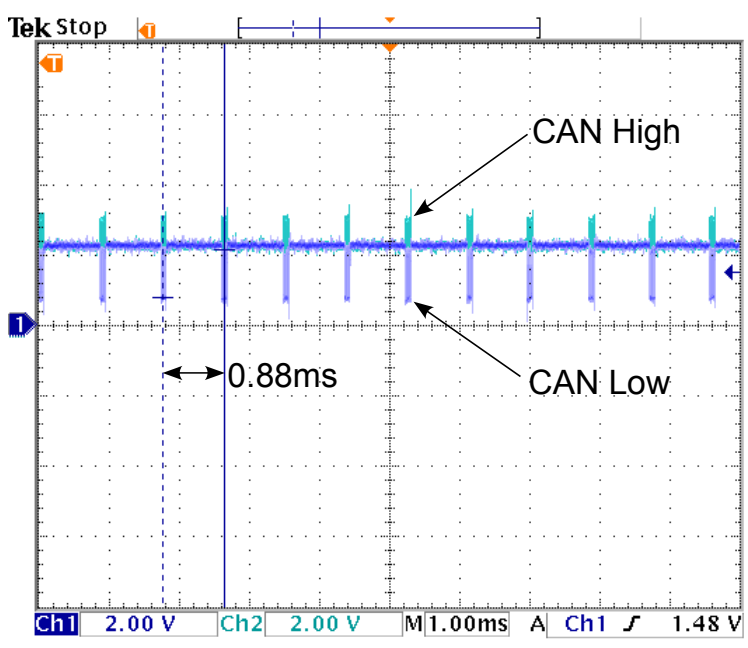

(a)

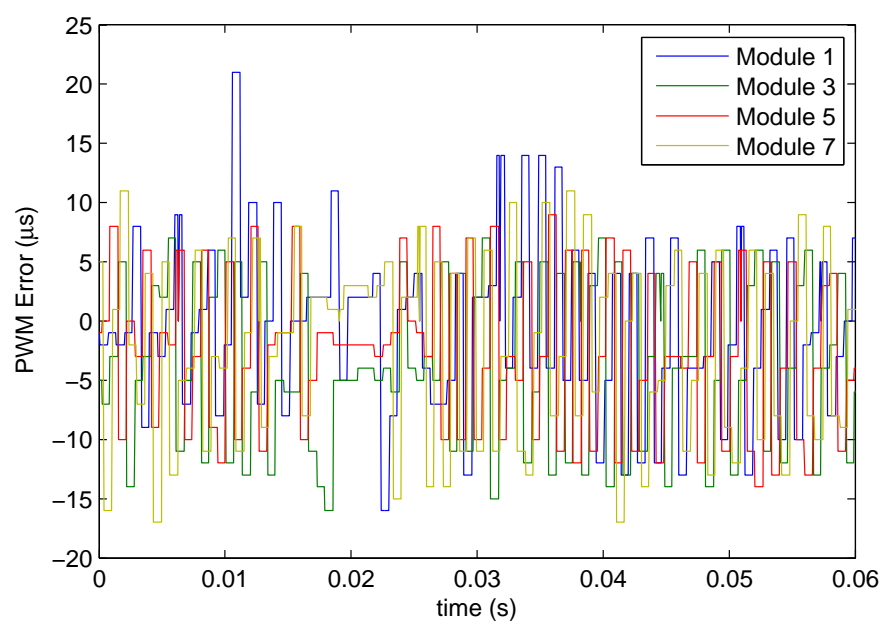

(b)

Fig. 12. PWM synchronisation (a) Activity on CAN bus with 12 modules, (b) Synchronisation error recorded by the module controllers.

but the chosen proportional gain gives a significant steady-state error, while also causing some high frequency instability in the applied voltage signal. Decreasing the proportional gain will reduce the applied voltage instability and increase the steady state error, while increasing the proportional gain will have the opposite effect.

Operation of the inverter in current limiting mode with a grid connection was also tested, and the results are shown in Fig.14 for stable operation and for operation with a high proportional gain leading to instability in the inverter current. It was found that the limit to the proportional gain for stable operation varied with the current demand, with a higher current demand requiring a lower gain to maintain stability. The dynamic response of the current controller will be shown later.

\section{Grid Voltage Estimation and Synchronisation}

The grid voltage magnitude and frequency reference values were captured from four modules while the inverter was connected to the grid, in order to verify the quality of the grid voltage tracking. The results are shown in Fig.15. The grid voltage reference is the peak voltage seen by each module, 


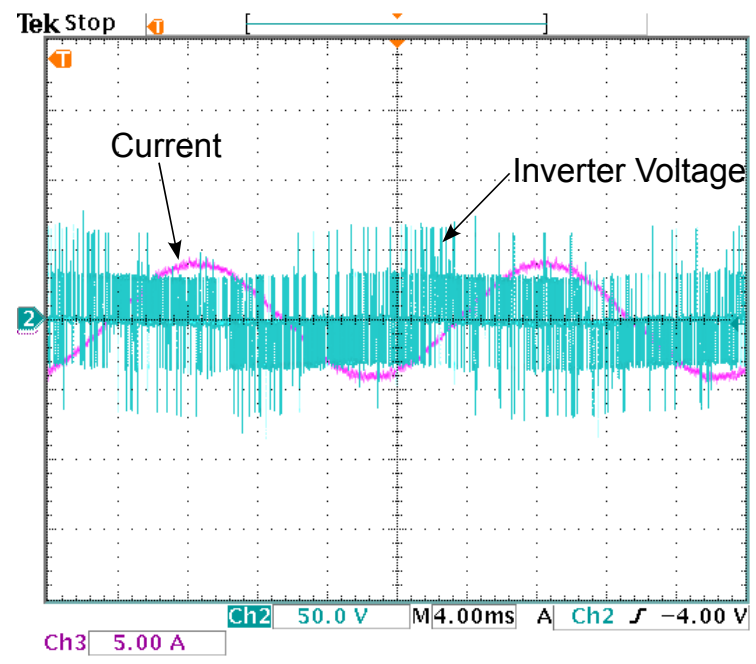

(a)

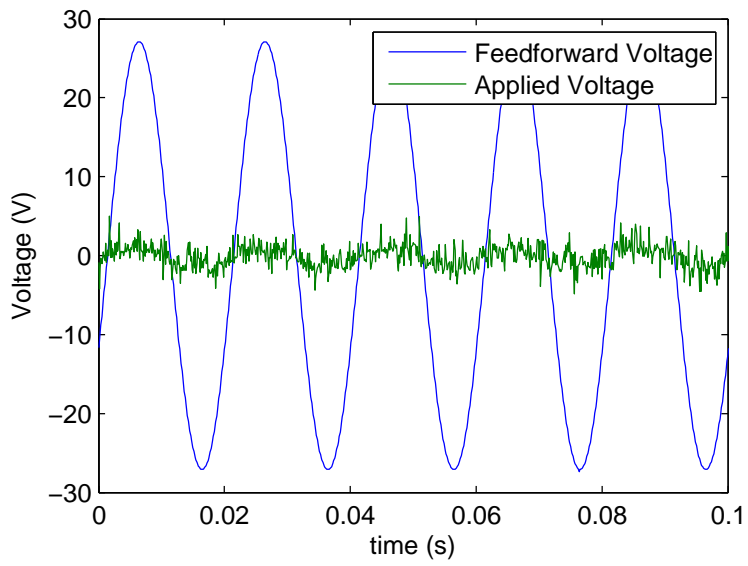

(b)

Fig. 13. Behaviour of the current limiting controller with the inverter terminals shorted (a) Measured inverter current and voltage, (b) Feedforward voltage and applied voltage signals per module.

with an RMS grid voltage of $230 \mathrm{~V}$ this is $\frac{\sqrt{2} \times 230 \mathrm{~V}}{12}=27.1 \mathrm{~V}$. Some high frequency noise is present in the frequency estimation, and some interference at the grid frequency in the voltage estimation but in general the noise levels are low.

The dynamic response of the grid voltage estimation controller can be seen when the inverter is connected to the grid while in an unsynchronised state. This was the method used to synchronise the inverter to the grid voltage, as the inverter has no way of measuring the grid voltage before it is connected. The response is shown in Fig.16, in which the grid and inverter voltage and current were recorded using an oscilloscope and the remaining quantities recorded on the controllers of several different modules. The current limiting mode was activated before the inverter was connected.

The initial grid frequency was almost the same as that of the module's reference frequencies, but a significant phase difference was used in order to achieve a worst case scenario. The current controllers are able to limit the current, but a significant transient current still flows, and causes the DClink voltage on the modules to increase. The time taken for the phase of the grid reference PLL to match that of the grid

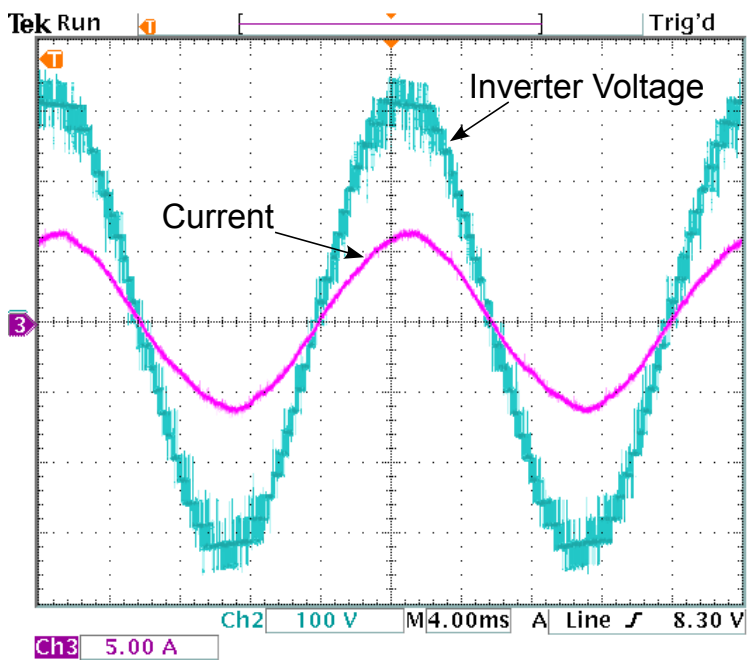

(a)

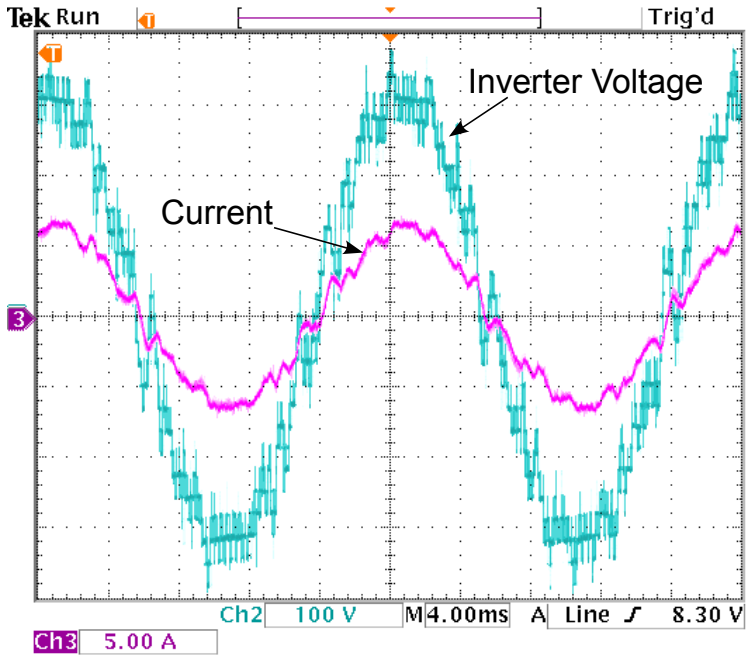

(b)

Fig. 14. Current limiting mode applied to grid connection (a) Stable operation $\left(K_{P}=4\right)$, (b) Unstable operation with higher proportional gain $\left(K_{P}=5\right)$.

voltage is limited by limits placed on the allowable frequency values, and a faster acquisition speed could be achieved if these are removed during synchronisation. The responses of all modules are identical, verifying the effectiveness of the synchronisation method using the CAN bus.

During the acquisition period, power flows from the grid into the inverter, which results in the DC-link voltage of the modules increasing significantly. Each module features a braking circuit which is able to dissipate some power into a resistor, but the capacity of this circuit is small, and not able to fully limit the DC-link voltage. The response speed of the DC-link voltage controller on the rectifier side is also limited to avoid interacting with the $2^{\text {nd }}$ harmonic ripple.

\section{Grid Fault Ride-through and Module Fault Tolerance}

Testing of the response to the loss of a module was carried out in the normal feedforward current control mode, with PWM switching. A more detailed discussion of the module fault response can be found in [16], where fundamental 

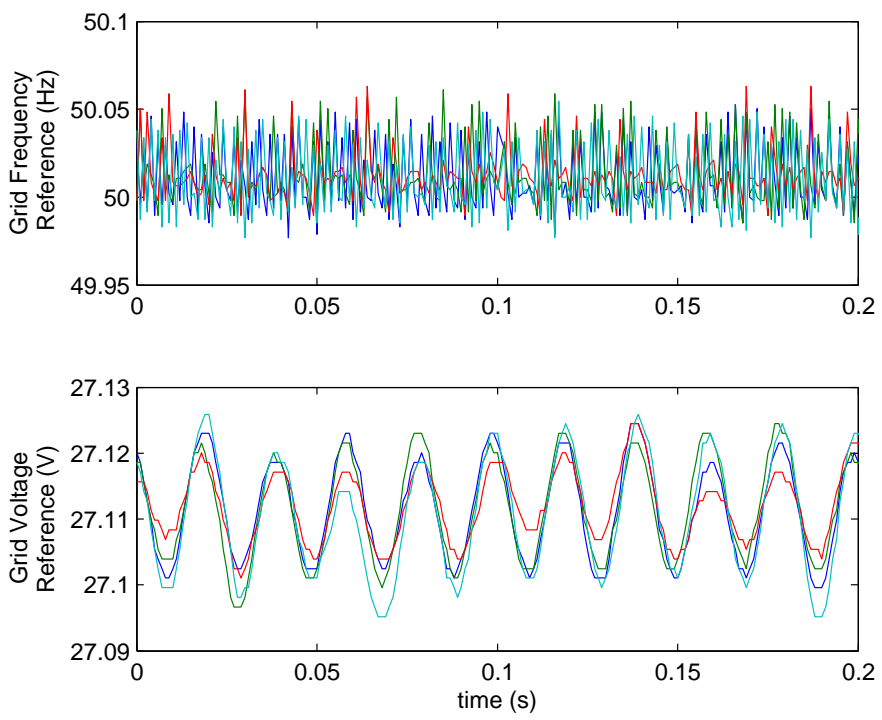

Fig. 15. Grid frequency and voltage references from four modules.
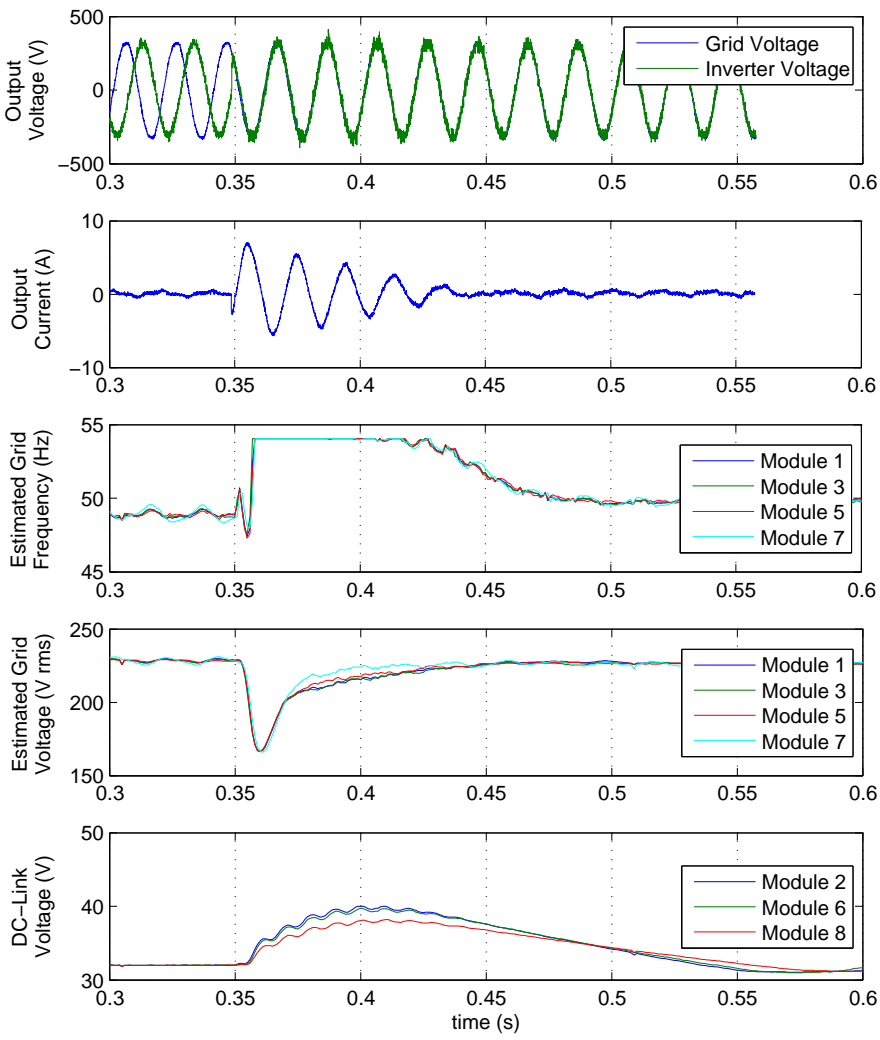

Fig. 16. Acquisition of the grid voltage and frequency when first connected.

frequency switching is used. The fault is emulated by having one module hold its output voltage at zero on a command from the host $\mathrm{PC}$, while also ceasing to send synchronisation messages on the CAN bus, which represents a complete failure of the module control system and activation of the bypass switch.

The response to a module loss is shown in Fig.17. The inverter output voltage and current were recorded on an oscilloscope, while the estimated grid voltage was obtained from one of the module controllers and scaled to the RMS value of the inverter with 12 modules. The remaining modules interpret the loss of one module as a step change in the grid voltage magnitude, and are able to adjust quickly, without entering the current limiting mode of operation. The interleaving of the PWM waveform is adjusted over a period of around $0.25 \mathrm{~s}$.
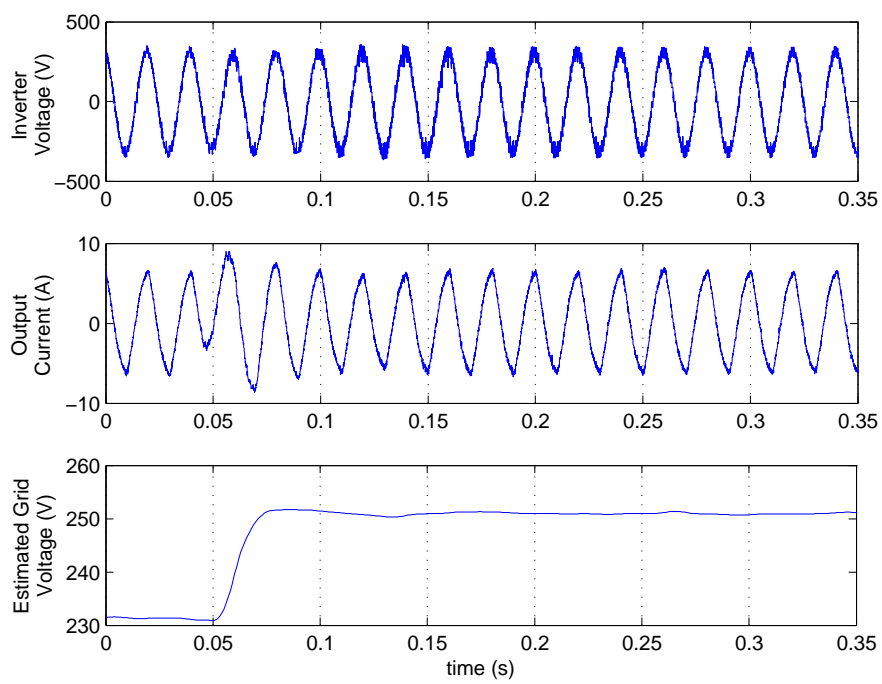

Fig. 17. Response of the system to the loss of a single module.

A system for emulating grid faults was not available, so an approximation of the grid fault performance was obtained by connecting the inverter to a resistive load bank. The grid frequency estimator was disabled, the current demand set to around $4 \mathrm{~A}$ and the resistance adjusted until that current was achieved with a $230 \mathrm{~V}$ output voltage. The feedforward current control mode was used, with PWM switching in each module. To emulate a grid fault, the resistance was quickly reduced to a low value by connecting an additional resistor in parallel with the load bank.

The response to the emulated grid fault is shown in Fig.18, where the inverter voltage and current were recorded using an oscilloscope and the other quantities recorded on the controllers of several modules. The drop in resistance causes a spike in the inverter current, triggering the current limiting mode of operation. The module controllers interpret the drop in resistance as a drop in grid voltage, and the estimated grid voltage is adjusted within two cycles of the inverter frequency.

The quick response of the grid voltage estimator, and the associated change in feedforward voltage, means that the steady state error from the current controller does not result in a significant over-current. The response of the grid voltage estimator is identical to that obtained in the module fault test, which uses a grid connection, and the current limiter has been shown to be capable of limiting the current during a short circuit at the turbine terminals, suggesting that the converter would be able to ride through a phase to ground fault.

A significant DC-link over-voltage occurs, which is due to the limitations in the response speed of the DC-link voltage controller implemented with the rectifier controller. The DClink voltage controller does not feature any feedforward signals from the grid voltage estimator, and the addition of such signals may help with limiting the overvoltage. 

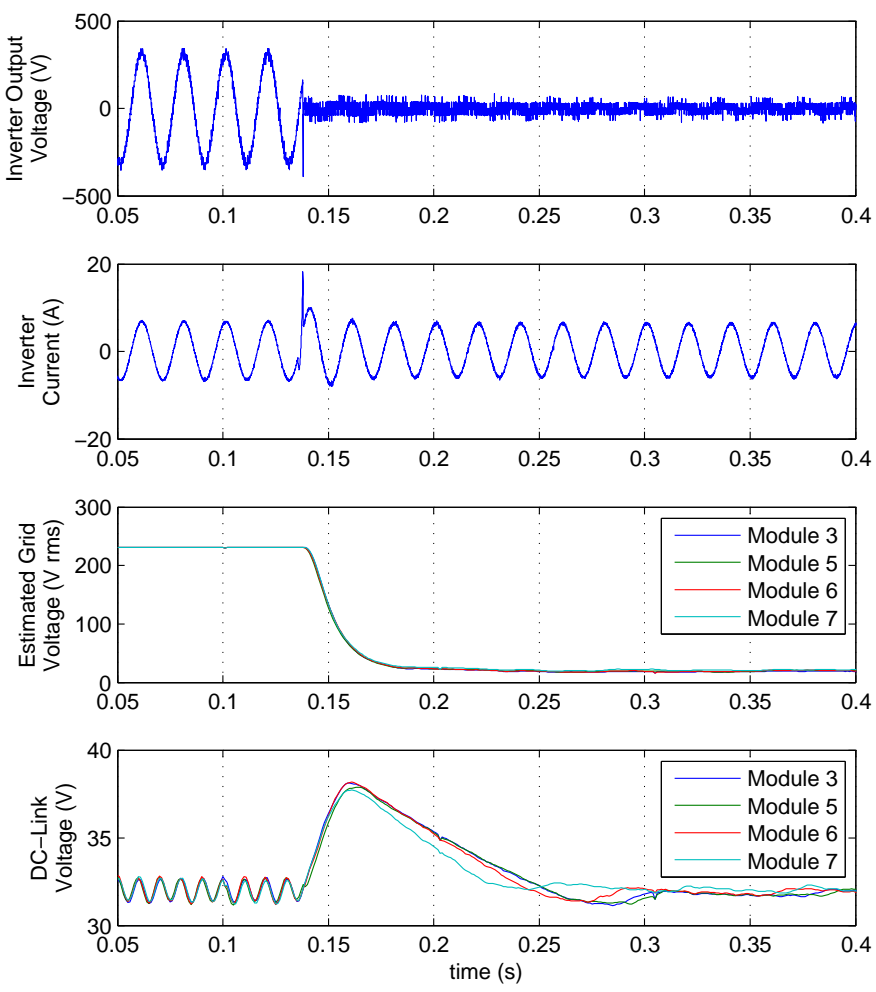

Fig. 18. Response of the system to a drop in grid voltage.

Distortion in the current waveform can be seen in Fig.17, even when the remaining modules have finished adjusting to the module loss, and this is due to distortion in the grid voltage. The current distortion is not present in Fig.14 or Fig.16 as the current limiting mode forces the current to be sinusoidal. Testing using a loadbank instead of a grid connection, as in Fig.18, also shows a sinusoidal current, indicating that the current distortion is due to the grid voltage.

\section{CONCLUSIONS}

A fault tolerant distributed control system has been proposed for a wind turbine grid interface based on a modular cascaded multilevel inverter, which allows both the synchronisation of the module switching waveforms and tracking of the grid voltage without the use of a central controller. Each individual module estimates the grid voltage magnitude and frequency, and the modules are synchronised over a CAN bus, which is also used to synchronise the module's PWM carriers. A current limiting system is implemented, which operates independently on all modules.

Operation of the system has been verified in normal conditions with a grid connection and emulated grid fault conditions using a load bank. The emulated grid fault triggers the current limiting mode which prevents over current, and the distributed controller quickly recognises the change in load and adjusts the output voltage demand. It is expected that the response will be similar in a real grid fault condition.

The inverter is able to synchronise with the grid frequency without damaging inrush currents, which is required after a grid fault is cleared or when first connecting to the grid. However, the synchronisation speed is limited by limits placed on the frequency range the controller can operate in, which could lead to significant DC-link over-voltage while synchronising. Removing this limit could boost the synchronisation speed. A faster grid frequency estimator could also be used while synchronising, with the controllers switching to a slower estimator when synchronised for better noise immunity.

Testing with a load bank suggests that the controller is able to rapidly react to a drop in the grid voltage caused by a grid fault, although this still results in a large DC-link over-voltage. The DC-link voltage controller cannot react to the voltage ripple at twice the grid frequency due to the single phase inverter, and this limits the response speed of the controller. A faster controller which does react to higher frequencies could be used during a grid fault, or a feedforward term based on the estimated grid voltage could be added to the controller.

These results were obtained using a test rig based on a single phase inverter of 12 modules, and would also be valid for a three phase inverter with the neutral point connected to ground, and subjected to a phase to ground fault. Additional flexibility and fault tolerance is possible in full three phase systems with a floating neutral point, but in this case the dominant fault type would be the phase to phase fault. This would be more difficult to handle, requiring a modified control strategy. A fault tolerant centralised carrier-based PWM scheme, for a converter with floating neutral point, is described in [37],

The proposed control system is most relevant to the offshore wind turbine application, where multi-pole generators, necessary to supply the isolated voltages, are often used, and accessibility is difficult leading to a desire for fault tolerance. The use of boost rectifiers to feed the DC-links means that the modules each include a microcontroller-based control system, so the additional control circuits are minimal. The control method could also be applied to other modular implementations of multilevel inverters, for example STATCOMs and HVDC converter stations, but these do not usually have powerful controllers on the individual modules, and these would need to be added, increasing cost.

\section{REFERENCES}

[1] G. J. W. van Bussel and M. B. Zaaijer, "Reliability, availability and maintenance aspects of large-scale offshore wind farms, a concepts study," in IMarEst, MAREC Conference, Newcastle, UK, Mar. 2001.

[2] F. Spinato, P. J. Tavner, G. J. W. van Bussel, and E. Koutoulakos, "Reliability of wind turbine subassemblies," IET Renew. Power Gener, vol. 3, no. 4, pp. 387-401, 2009.

[3] D. McMillan and G. W. Ault, "Techno-economic comparison of operational aspects for direct drive and gearbox-driven wind turbines," IEEE Trans. Energy Convers., vol. 25, no. 1, pp. 191-198, Mar. 2010.

[4] M. Liserre, R. Cardenas, M. Molinas, and J. Rodriguez, "Overview of multi-MW wind turbines and wind parks," IEEE Trans. Ind. Electron., vol. 58, no. 4, pp. 1081-1095, Apr. 2011.

[5] J. Li, S. Bhattacharya, and A. Q. Huang, "A new nine-level active NPC (ANPC) converter for grid connection of large wind turbines for distributed generation," IEEE Trans. Power Electron., vol. 26, no. 3, pp. 961-972, Mar. 2011.

[6] C. L. Xia, X. Gu, T. N. Shi, and Y. Yan, "Neutral-point potential balancing of three-level inverters in direct-driven wind energy conversion system," IEEE Trans. Energy Convers., vol. 26, no. 1, pp. 18-29, Mar. 2011.

[7] M. Abbes, J. Belhadj, and A. Bennani, "Design and control of a directdrive wind turbine equipped with multilevel converters," Renewable Energy, vol. 35, no. 5, pp. 936-945, May 2010. 
[8] R. Melicio, V. M. F. Mendes, and J. P. S. Catalao, "Harmonic assessment of variable-speed wind turbines considering converter control malfunction," IET Renewable Power Generation, vol. 4, no. 2, pp. 139-152, Mar. 2010.

[9] M. Malinowski, S. Stynski, W. Kolomyjski, and M. P. Kazmierkowski, "Control of three-level PWM converter applied to variable-speed-type turbines," IEEE Trans. Ind. Electron., vol. 56, no. 1, pp. 69-77, Jan. 2009.

[10] C. H. Ng, M. A. Parker, L. Ran, P. J. Tavner, J. R. Bumby, and E. Spooner, "A multilevel modular converter for a large, light weight wind turbine generator," IEEE Trans. Power Electron., vol. 23, no. 3, pp. 1062-1074, May 2008.

[11] S. S. Gjerde and T. M. Undeland, "The best suitable multilevel converters for offshore wind power generators without transformers," in The 2010 International Power Electronics Conference, 2010.

[12] J. S. Lai and F. Z. Peng, "Multilevel converters - a new breed of power converters," IEEE Trans. Appl. Ind., vol. 32, no. 3, pp. 509-517, 1996.

[13] P. W. Hammond, "A new approach to enhance the power quality for medium voltage drives," IEEE Trans. Appl. Ind., vol. 33, no. 1, pp. 201-208, 1997.

[14] P. Lezana, J. Pou, T. A. Meynard, J. P. Rodriguez, S. Ceballos, and F. Richardeau, "Survey on fault operation on multilevel inverters," IEEE Trans. Ind. Electron., vol. 57, no. 7, pp. 2207-2218, Jul. 2010.

[15] W. Song and A. Q. Huang, "Fault-tolerant design and control strategy for cascaded h-bridge multilevel converter-based STATCOM," IEEE Trans. Ind. Electron., vol. 57, no. 8, pp. 2700-2708, Aug. 2010.

[16] M. A. Parker, C. H. Ng, and L. Ran, "Fault tolerant control for a modular generator-converter scheme for direct-drive wind turbines," IEEE Trans. Ind. Electron., vol. 58, no. 1, pp. 305-315, 2011.

[17] E. Spooner, P. Gordon, J. R. Bumby, and C. D. French, "Lightweight ironless-stator PM generators for drect-drive wind turbines," IEE Proc. Electr. Power Appl., vol. 152, no. 1, pp. 17-26, 2005.

[18] Z. Chen and E. Spooner, "A modular, permanent-magnet generator for variable speed windturbines," in Seventh international conference on electrical machines and drives, Durham, UK, 1995, pp. 453-457.

[19] B. C. Mecrow, A. G. Jack, D. J. Atkinson, S. R. Green, G. J. Atkinson, A. King, and B. Green, "Design and testing of a four-phase faulttolerant permanent-magnet machine for an engine fuel pump," IEEE Trans. Energy Convers., vol. 19, no. 4, pp. 672-678, 2004.

[20] H. Polinder, F. F. A. van der Pijl, G.-J. de Vilder, and P. J. Tavner, "Comparison of direct-drive and geared generator concepts for wind turbines," IEEE Trans. Energy Convers., vol. 21, no. 3, pp. 725-733, 2006.

[21] P. C. Loh, D. G. Holmes, and T. A. Lipo, "Implementation and control of distributed PWM cascaded multilevel inverters with minimal harmonic distortion and common-mode voltage," IEEE Trans. Power Electron., vol. 20, no. 1, pp. 90-99, Jan. 2005.

[22] C.-L. Chen, Y. Wang, J.-S. Lai, Y.-S. Lee, and M. D, "Design of parallel inverters for smooth mode transfer microgrid applications," IEEE Trans. Power Electron., vol. 25, no. 1, pp. 6-15, Jan. 2010.

[23] W. Yao, M. Chen, J. Matas, J. M. Guerrero, and Z.-M. Qian, "Design and analysis of the droop control method for parallel inverters considering the impact of the complex impedance onthe power sharing," IEEE Trans. Ind. Electron., vol. 58, no. 2, pp. 576-588, Feb. 2011.

[24] K. I. Hwu and Y. H. Chen, "Current sharing control strategy based on phase link," IEEE Trans. Ind. Electron., vol. 59, no. 2, pp. 701-713, Feb. 2012.

[25] Y. Zhang and H. Ma, "Theoretical and experimental investigation of networked control for parallel operation of inverters," IEEE Trans. Ind. Electron., vol. 59, no. 4, pp. 1961-1970, Apr. 2012.

[26] P. Lezana and G. Ortiz, "Extended operation of cascaded multicell converters under fault conditions," IEEE Trans. Ind. Electron., vol. 56, no. 7, pp. 2697-2703, 2009.

[27] J. Schlabbach, "Low voltage fault ride through criteria for grid connection of wind turbine generators," in 5th International Conference on European Electricity Market. EEM 2008, May 2008.

[28] S. Alepuz, S. Busquets-Monge, J. Bordonau, J. Martinez-Velasco, C. Silva, J. Pontt, and J. Rodriquez, "Control strategies based on symmetrical components for grid-connected converters under voltage dips," IEEE Trans. Ind. Electron., vol. 56, no. 6, Jun. 2009.

[29] CAN Specification, Version 2.0, Robert Bosch GmbH Std., 1991.

[30] M. Barranco, J. Proenza, and L. Almeida, "Quantitative comparision of the error-containment capabilities of a bus and star topology in CAN networks," IEEE Trans. Ind. Electron., vol. 58, no. 3, pp. 802-813, Mar. 2011.
[31] F. Baronti, E. Petri, S. Saponara, L. Fenucci, R. Roncella, R. Saletti, P. D'Abramo, and R. Serventi, "Design and verification of hardware building blocks for high-speed and fault-tolerant in-vehicle networks,' IEEE Trans. Ind. Electron., vol. 58, no. 3, pp. 792-801, Mar. 2011.

[32] N. Mohan, T. M. Undeland, and W. P. Robbins, Power Electronics: Converters, Applications and Design. John Wiley \& Sons, 2003, ch. 8, pp. 211-221.

[33] D. J. Perreault and J. G. Kassakian, "Distributed interleaving of paralleled power converters," IEEE Trans. Circuits Syst. I, vol. 44, no. 8, pp. 728-734, Aug. 1997.

[34] I. Agirman and V. Blasko, "A novel control method of a VSC without AC line voltage sensors," IEEE Trans. Ind. Appl., vol. 39, no. 2, pp. 519-524, Mar. 2003.

[35] A. S. Tannenbaum and M. van Steen, Distributed Systems: Principles and Paradigms. Prentice Hall, 2002, ch. 5, pp. 241-258.

[36] L. Rodruigues, M. Guimaraes, and J. Rufino, "Fault-tolerant clock synchronization in CAN," in RTSS'98, Madrid, Spain, Dec. 1998.

[37] F. Carnielutti, H. Pinheiro, and C. Rech, "Generalized carrier-based modulation strategy for cascaded multilevel converters operating under fault conditions," IEEE Trans. Ind. Electron., vol. 59, no. 2, pp. 679-689, Feb. 2012.

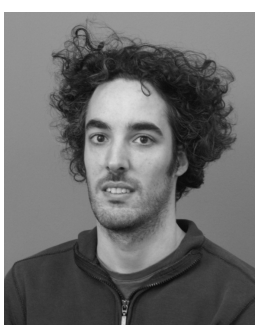

Max Parker received his Engineering Doctorate (Eng.D.) degree in Power Electronics, Drives and Machines from the University of Newcastle Upon Tyne, UK, in 2009, with research carried out in the School of Engineering, Durham University and sponsored by the New and Renewable Energy Centre (NaREC) in Blyth, UK. He is currently working as a research fellow with the Institute for Energy in the Environment at the University of Strathclyde, Glasgow, UK, investigating collection network architectures for large offshore wind farms. His research interests include digital control of power electronic systems, including distributed control systems, and control of large wind turbines and the associated power systems.

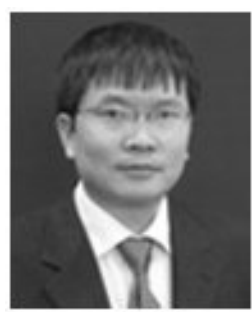

Li Ran received the Ph.D. degree in Power Systems Engineering from Chongqing University, Chongqing, China, in 1989. He participated in the commissioning of Gezhouba-Shanghai HVDC System in 1989. Between 1992 and 1999, he was a Research Associate with the University of Aberdeen, Aberdeen, UK; the University of Nottingham, Nottingham, UK and Heriot-Watt University, Edinburgh, UK. He was a Senior Lecturer in Power Electronics with Northumbria University, Newcastle Upon Tyne, UK between 1999 and 2003, and was seconded to Alstom Power Conversion at Kidsgrove, UK in 2001. Currently, he is a Professor in Electrical Power and Control in the School of Engineering and Computing Sciences, Durham University, Durham, UK. His research interests include the application of power electronics in power systems and renewable energy systems, such as wave and wind energy converters.

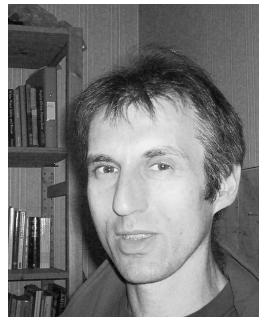

Steven Finney obtained an MEng degree in Electrical and Electronic Engineering from Loughborough University of Technology in 1988. He worked for the Electricity Council Research Centre before joining the power electronics research group at Heriot-Watt University in 1990, receiving the award of $\mathrm{PhD}$ in 1994. From 1994 to 2005 he was a member of academic staff at Heriot-Watt University. In 2005 he moved to the University of Strathclyde where he is and currently Professor with the Institute of Energy and Environment, specialising in power electronic systems. His research interests include the power electronics for high power applications and the management of distributed energy resources. 